\title{
Docetaxel weekly regimen in conjunction with RF hyperthermia for pretreated locally advanced non-small cell lung cancer: a preliminary study Zhu Jiang*1, Wang Yan², Jiang Ming ${ }^{1}$ and Yang $\mathrm{Yu}^{1}$
}

\author{
Address: ${ }^{1}$ Cancer Center of West China (Hua Xi) Hospital, Si Chuan University, Guo Xue Street, City of Cheng Du, Si Chuan, 610041, China and \\ ${ }^{2}$ West China 2nd University Hospital, Si Chuan University, Ren Min Nan Road, City of Cheng Du, Si Chuan, 610041, China \\ Email: Zhu Jiang* - zhujiang1@medmail.com.cn; Wang Yan - while678@sina.com; Jiang Ming - mingminyu@gmail.com; \\ Yang Yu - yangyuflying@hotmail.com \\ * Corresponding author
}

Published: 6 October 2007

BMC Cancer 2007, 7:189 doi:10.1186/147/-2407-7-189
Received: 20 May 2007

Accepted: 6 October 2007

This article is available from: http://www.biomedcentral.com//47/-2407/7//89

(c) 2007 jiang et al; licensee BioMed Central Ltd.

This is an Open Access article distributed under the terms of the Creative Commons Attribution License (http://creativecommons.org/licenses/by/2.0), which permits unrestricted use, distribution, and reproduction in any medium, provided the original work is properly cited.

\begin{abstract}
Background: To evaluate the feasibility and therapeutic effect of chemotherapy combined with regional radio frequency hyperthermia for pretreated locally advanced non-small cell lung cancer.

Methods: 29 patients with stage III non-small cell lung cancer were enrolled in present study, received chemotherapy up to 4 cycles and radio frequency hyperthermia up to 32 times. The primary end points were grade 3,4 hematological or non-hematological toxicities and progression free survival, the secondary end points were response rate, tumor control rate and overall survival. Method of Kaplan-Meier was used for the survival analysis.
\end{abstract}

Results: 21 patients completed their arranged treatments. The most common grade 3,4 toxicity was neutropenia (24.1\%). Median progression free survival was 4 months (range $0-13$ months), one year progression free survival rate was $10.3 \%$. Overall response rate was $25.9 \%$, tumor control rate was $66.6 \%$. Median overall survival was II months (range $2-18^{+}$months), one year overall survival rate was $44.8 \%$.

Conclusion: Treatment of chemotherapy in conjunction with regional hyperthermia was safe and well tolerant, it suggested an impressive tumor control rate and an acceptable one year progression free survival. Further study might be needed.

\section{Background}

Non-small cell lung cancer accounts for at least $80 \%$ of all lung neoplasma, and about $35 \%$ of these patients present with locally advanced unresectable disease [1]. Systemic chemotherapy with the platinum-containing regimens plus concurrent regional radiation is generally accepted as the standard first-line treatment for inoperable locally advanced non-small cell lung cancer, meta-analysis confirmed the response and survival benefits, but the large number of patients will experience disease progression or tumor relapse [2-6]. For patients with a good performance status, second-line chemotherapy is recommended. Several third-generation chemotherapeutic agents had been evaluated in the second line setting, docetaxel maybe the most extensively studied one [7-10]. Recent studies indicated that second-line chemotherapy with docetaxel weekly as a single-agent regimen for pretreated non-small cell lung cancer was well tolerant and had an acceptable 
response rate and a reasonable median survival time about 26.1 weeks $[7,11,12]$. Obviously, neither physicians nor patients are satisfied with this.

Empirical studies indicated that heat played a lethal effect to human tumor cell lines, and heat enhanced cytotoxic effect of chemotherapeutics [13-15]. Along with the development of technology, hyperthermia improves therapeutic effect of superficial tumors, soft tissue sarcoma, osteosarcoma, prostate cancer, breast cancer and some recurrent or advanced solid tumors [16-21]. There are rare reports that demonstrate the advantage of adding hyperthermia to chemotherapy as the second-line therapy for pretreated locally advanced non-small cell lung cancer. In present study, we combined docetaxel weekly chemotherapy with external regional radio frequency (RF) hyperthermia as the second-line treatment for patients with inoperable stage III non-small cell lung cancer who had failed to response to the prior platinum-containing chemotherapy. The toxicities and progression free survive (PFS) were primarily investigated.

\section{Methods}

\section{Patients selection}

Eligible patients must had histological or cytological proof to be inoperable stage IIIa or IIIb non-small cell lung cancer, and should have at least one measurable lesion. They experienced only one platinum-containing regimen as the first-line treatment, whether accompanied with irradiation or not. They failed to respond to the firstline treatment, and proved to be still inoperable by spiral computed tomograph. In addition, patients should be with a ECOG performance status $\leq 2$, and have normal hematological index (neutrophil count $\geq 2 \times 10^{9} / 1$, platelet count $\geq 100 \times 10^{9} / \mathrm{l}$, haemoglobin $\geq 100 \mathrm{~g} / \mathrm{l}$ ) and acceptable biochemical analysis result (normal bilirubin level, alanine aminotransferase $\leq 2.5 \times$ upper limit of normal (ULN) and serum creatinine level $\leq 1.5 \times$ ULN). Patients with metal foreign matter, fever $\left(\geq 38^{\circ} \mathrm{C}\right)$, significant hemorrhagic tendency, and seriously impaired function of lung or heart were excluded. Every patient enrolled in this study had signed a written informed consent form approved by Si Chuan University Hua Xi Medical Ethics Committee, which also approved the study protocol.

\section{Chemotherapy regimen}

A regimen of docetaxel $40 \mathrm{mg} / \mathrm{m}^{2}$ intravenous infusion on day1, 8 and 15, repeated every 4 weeks was chosen. Docetaxel was administered intravenously within 1 hour. Prophylactic oral corticosteroid premedication (dexamethasone $8 \mathrm{mg}$ ) was given 3 times over 2 days. Target sum of chemotherapy would be 4 cycles.

Dose adjustment should be done when grade 4 hematological or grade 3,4 non-hematological toxicities appeared, a dose reduction was of $25 \%$ in subsequent cycles. Docetaxel infusion could not be delayed for over 2 weeks since patient discontinuation.

\section{Hyperthermia regimen}

We used a radio frequency external heat system (Ho Kai company, China) working frequency was $13.8 \mathrm{MHz}$ to perform regional hyperthermia. Primary lesion was chosen to be the target area, covered by an applicator $20 \mathrm{~cm}$ in diameter. Hyperthermia was administered 1 hour after chemotherapeutics were given, the total heated time was up to 60 minutes, twice a week, aimed to 32 times, interval between 2 procedures should exceed 48 hours. Target temperature ranged from $41^{\circ} \mathrm{C}$ to $43^{\circ} \mathrm{C}$, we instructed every patient to mention any abnormal feelings, so that we could adjust settings such as power output, or place a water bolus to ease the uncomfortable.

\section{Evaluation of response and toxicity}

The response had been estimated within a week after every 2 cycles of chemotherapy were given, and to be confirmed in 4 weeks of responding patients. We used contrastenhanced spiral computed tomograph to measure the largest diameter of target tumor, response criteria was based on Response Evaluation Criteria In Solid Tumors (RECIST)[22]. Toxicity evaluation was done in all patients according to NCI CTC version 2.0 [23].

\section{Follow up}

Eligible patients were visited once a month after treatment starting, their PFS and overall survival (OS) time was recorded. Disease evaluation was performed every 3 months or when necessary. The time limit of follow-up was 18 months in present study.

\section{Statistical analysis}

Main objective of present study was to evaluate the safety and therapeutic effect of docetaxel weekly chemotherapy combined with RF hyperthermia for pretreated locally advanced non-small cell lung cancer. The primary end points were grade 3,4 hematological or non-hematological toxicities and PFS, the secondary end points were response rate, tumor control rate and OS.

Kaplan-Meier survival curve was used to describe PFS and OS. Statistical work was performed by soft ware SPSS 13.0 (SPSS Inc. USA). Lost patients were recorded as death, their PFS were calculated up to the last visit as well as OS, except they had already experienced tumor progression.

\section{Results \\ Patients' characteristics}

From June 2005 to December 2005, 29 pretreated patients with stage III non-small cell lung cancer were included in this study, 8 patients in stage IIIb accompanied with pleu- 
ral effusion, who were not suitable for radiation. And other 10 patients refused to sign the informed consent form for radiotherapy. Overview of this study was fully explained to every eligible patient, every enrolled patient had signed an informed consent form and asked to keep one copy. Patients' characteristics were presented in Table 1.

\section{Treatment exposure}

249 docetaxel infusions and 626 times of hyperthermia were administered totally. Median dosage of docetaxel was $40 \mathrm{mg} / \mathrm{m}^{2}$ (range, $30-40 \mathrm{mg} / \mathrm{m}^{2}$ ), median endurable temperature was $42.3^{\circ} \mathrm{C}$ (range, $41.3-43.0^{\circ} \mathrm{C}$ ). There were 13 patients $(44.8 \%)$ completing 4 cycles of chemotherapy and 32 times of hyperthermia, 2 patients $(6.9 \%)$ had been administered only 1 cycle of chemotherapy and 2 times of hyperthermia.

\section{Toxicity}

8 patients $(27.6 \%)$ discontinued study treatment, 6 of them due to toxicities: 4 because of grade 3 neutropenia, and 2 because of grade 4 neutropenia; the other 2 patients withdrew their informed consent form. No patient terminated treatment because of the side effect of RF hyperthermia.

6 patients (20.7\%) experienced a dose reduction to 30 $\mathrm{mg} / \mathrm{m}^{2}$ due to toxicities (5 patients due to neutropenia, 1 patient due to arthralgia).

Table I: Patients' characteristics

\begin{tabular}{lll}
\hline Characteristics & Number of patients & Percentage \\
\hline $\begin{array}{l}\text { Patients treated } \\
\text { Age }\end{array}$ & 29 & - \\
Median & 57 & - \\
Range & $35-72$ & - \\
Gender & & \\
Male & 21 & 72.4 \\
Female & 8 & 27.6 \\
Histological subtype & & \\
Squamous carcinoma & 11 & 37.9 \\
Adenocarcinoma & 18 & 62.1 \\
Stage & & \\
IIla $\left(\mathrm{T}_{2} \mathrm{~N}_{2} \mathrm{M}_{0} / \mathrm{T}_{3} \mathrm{~N}_{2} \mathrm{M}_{0}\right)$ & $12(8 / 4)$ & 41.4 \\
IIIb $\left(\mathrm{T}_{2} \mathrm{~N}_{3} \mathrm{M}_{0} / \mathrm{T}_{4} \mathrm{~N}_{1} \mathrm{M}_{0} / \mathrm{T}_{4} \mathrm{~N}_{2} \mathrm{M}_{0}\right)$ & $17(2 / 8 / 7)$ & 58.6 \\
ECOG performance status & & \\
0 & 12 & 41.4 \\
I & 12 & 41.4 \\
2 & 5 & 17.2 \\
Prior chemotherapy (cycles) & & $48.3 \%$ \\
Gemcitabine and cisplatin & $14(46)$ & $27.6 \%$ \\
Vinorelbine and cisplatin & $8(2 \mathrm{I})$ & $37.9 \%$ \\
Paclitaxel and cisplatin & $7(26)$ & \\
Prior radiotherapy & 11 & \\
& &
\end{tabular}

Treatment delays were applied in 5 patients (17.2\%), 4 delays occurred due to neutropenia, the other one occurred due to abnormal level of alanine aminotransferase $(>2.5 \times \mathrm{ULN})$.

3 patients (10.3\%) experienced grade 1 empyrosis after heated, no related treatment was administered. This side effect released in 48 hours, not even one time of hyperthermia was delayed for this reason.

Main toxicities were summarized in Table 2.

\section{Response}

There were 27 patients (93.1\%) who had been evaluated for response. No patient achieved a complete remission (CR), 7 patients (25.9\%) achieved a partial remission (PR), 11 patients $(40.7 \%)$ were evaluated as a stable disease (SD), and 9 patients (33.3\%) experienced a progression disease (PD). Overall response rate was $25.9 \%$, tumor control rate $(\mathrm{CR}+\mathrm{PR}+\mathrm{SD})$ was $66.6 \%$.

\section{Survival analysis}

The median follow-up time was 16 months (range 12-18 months), 4 patients (13.8\%) were lost at follow up, their PFS/OS (months) was recorded as following: 0/2, 0/2, $0 /$ 5, 0/7. Median PFS was 4 months (range 0-13 months, 95\% CI: 1.9-6.1 months), one year progression free survival rate was $10.3 \%$ (Figure 1 ). Median OS was 11 months (range 2-18+ months, 95\% CI: 9.3-12.8 months), one year survival rate was $44.8 \%$ (Figure 2 ). At the time of analysis, 5 patients were still alive.

Table 2: Main toxicities per patient

\begin{tabular}{lllll}
\hline Toxicity & Grade I & Grade 2 & Grade 3 & Grade 4 \\
\hline Hematological & & & & \\
Hemoglobin & $2(6.9 \%)$ & 0 & 0 & 0 \\
Neutrophils & $5(17.2 \%)$ & $4(I 3.8 \%)$ & $5(17.2 \%)$ & $2(6.9 \%)$ \\
Platelets & $I(3.4 \%)$ & $I(3.4 \%)$ & 0 & 0 \\
Non-hematological & & & & \\
Palpitation & $I(3.4 \%)$ & - & - & - \\
Edema & $2(6.9 \%)$ & $I(3.4 \%)$ & 0 & 0 \\
Fatigue & $6(20.7 \%)$ & $2(6.9 \%)$ & 0 & 0 \\
Sweating & $4(13.8 \%)$ & 0 & - & - \\
Weight loss & $3(10.3 \%)$ & $I(3.4 \%)$ & 0 & - \\
Alopecia & $5(17.2 \%)$ & $2(6.9 \%)$ & - & - \\
Nausea & $5(I 7.2 \%)$ & $2(6.9 \%)$ & $I(3.4 \%)$ & - \\
Taste disturbance & $I(3.4 \%)$ & 0 & - & - \\
Vomiting & $2(6.9 \%)$ & $3(I 0.3 \%)$ & 0 & 0 \\
SGOT (AST) & $3(I 0.3 \%)$ & 0 & $I(3.4 \%)$ & 0 \\
SGPT (ALT) & $I(3.4 \%)$ & $I(3.4 \%)$ & $I(3.4 \%)$ & 0 \\
Insomnia & $3(I 0.3 \%)$ & 0 & 0 & - \\
Arthralgia & $2(6.9 \%)$ & 0 & $I(3.4 \%)$ & 0 \\
Headache & $2(6.9 \%)$ & 0 & 0 & 0 \\
Myalgia & 0 & 0 & $I(3.4 \%)$ & 0 \\
& & & &
\end{tabular}




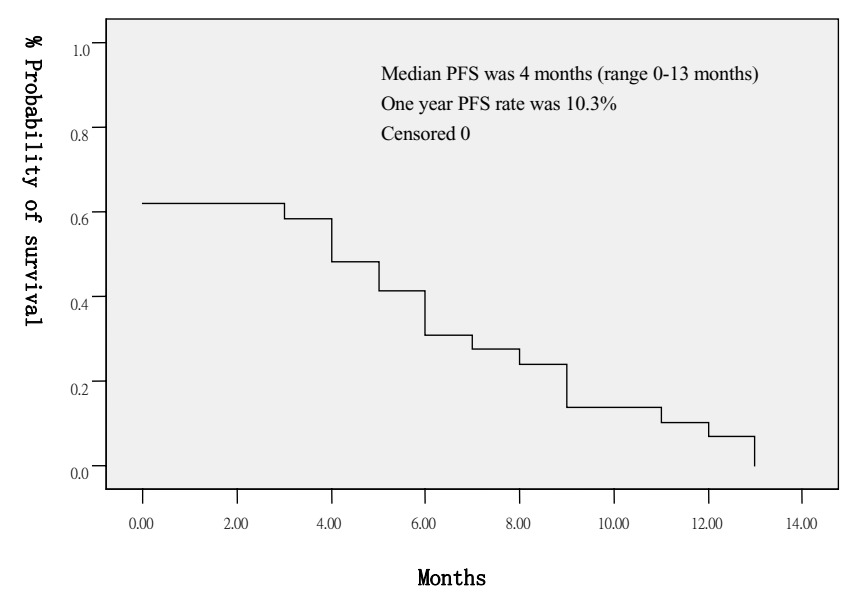

Figure I

Progression free survival.

\section{Discussion}

Docetaxel is recommended for second-line chemotherapy of non-small cell lung cancer, and weekly administration regimen showed a good safety, but recent studies resulted that the response rate and survive was still poor [12]. There are rare studies about hyperthermia for lung cancer, even it had been reported to improve the therapeutic efficacy in some drug insensitive tumors such as prostate cancer and soft tissue sarcoma $[17,18,20]$.

Structure of vascular in malignant tissue is great different from normal tissue, it was reported that the blood flow rate in normal tissue would be 30 times greater than tumor tissue [24]. This difference makes temperature of tumor tissue significantly higher than normal tissue under the same heat condition. Cytotoxic effect of several antitumor agents include docetaxel can be enhanced by raising

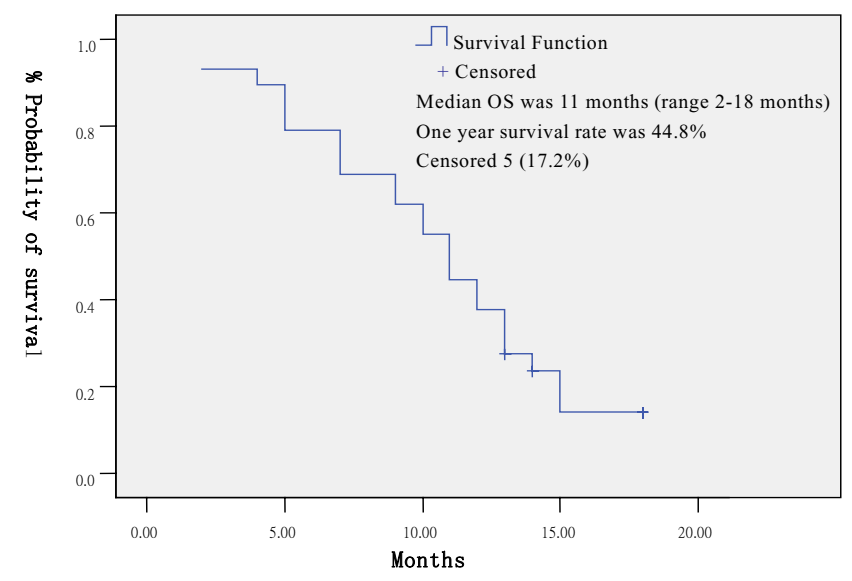

Figure 2

Overall survival. temperature [25]. Hyperthermia also shows as a complementation of radiotherapy [26]. RF hyperthermia is powered by electromagnetic wave of a certain wavelength, it has the ability to go through whole human body and transforms to heat when different mediator encountered. Current study was designed to evaluate feasibility and efficacy of docetaxel plus RF hyperthermia for patients failed to response to prior platinum-containing chemotherapy.

A total of 29 eligible patients enrolled in present study, 12 patients were of stage IIIa, 17 patients were of stage IIIb. 21 patients $(72.4 \%)$ completed the arranged study treatment, while 8 patients $(27.6 \%)$ discontinued. Main hematological toxicity was neutropenia, 7 patients (24.1\%) experienced Grade 3,4 neutropenia, most of them were grade 3 . With G-CSF hypodermic injection, this toxicity was well controlled. None of grade 4 nonhematological toxicities was observed, but grade 3 nausea, transaminase increasing, arthralgia and myalgia had been observed. Only 3 patients experienced grade 1 empyrosis, and they all self-recovered. Results above showed the comparable toxicities[7,11], it might indicate that regional RF hyperthermia does not increase the toxicity of chemotherapy.

The therapeutic efficacy of the study treatment was acceptable, a response rate of $25.9 \%$ and a tumor control rate of $66.6 \%$ were better than docetaxel alone. A median PFS of 4 months and a median OS of 11 months might not be satisfied, but compared with docetaxel alone (median OS ranged from 6.4 to 9.2 months), these results were encouraging $[7,8]$.

\section{Conclusion}

Docetaxel weekly regimen in conjunction with regional RF hyperthermia acted as the second-line treatment for pretreated locally advanced non-small cell lung cancer was safe and well tolerant. The results of current study also suggested advantages in response and survival. A further phase III study is supported by these results.

\section{Competing interests}

The author(s) declare that they have no competing interests.

\section{Authors' contributions}

ZJ designed this study and was in charge of the clinical protocol. WY analyzed the data and drafted the manuscript. ZJ, JM and YY enrolled patients in the clinical protocol. All authors read and approved the final manuscript.

\section{Acknowledgements}

The authors would like to thank all their colleagues who participated in this study: Prof. Hou Mei; Dr. Luo De Yun; Dr.Qiu Meng; Dr. Li Lu; Dr. Yan Xi; Dr. Gou Hong Feng (Cancer center of West China hospital). Special thanks 
for Miss Diao Yong Shu, Miss Li Hong and Miss Huang Zong Qiong (Nursing department of West China hospital).

\section{References}

I. Jemal A, Tiwari RC, Murray T: Cancer Statistics, 2004. CA Cancer J Clin 2004, 54:8-29.

2. American Society of Clinical Oncology: Clinical practice guidelines for the treatment of unresectable non-small-cell lung cancer. J Clin Oncol 1997, I5:2996-3018.

3. Joan HS, David H, Chandra PB: Comparison of Four Chemotherapy Regimens for Advanced Non-Small-Cell Lung Cancer. $N$ Engl J Med 2002, 346:92-98.

4. Comella P, Filippelli G, De Cataldis G: Efficacy of the combination of cisplatin with either gemcitabine and vinorelbine or gemcitabine and paclitaxel in the treatment of locally advanced or metastatic non-small-cell lung cancer: a phase III randomised trial of the Southern Italy Cooperative Oncology Group (SICOG 0 I O I). Ann Oncol 2007, I 8:324-330.

5. D'Addario G, Pintilie M, Leighl NB: Platinum-Based Versus NonPlatinum-Based Chemotherapy in Advanced Non-SmallCell Lung Cancer: A Meta-Analysis of the Published Literature. J Clin Oncol 2005, 23:2926-2936.

6. Auperin A, Pechoux CL, Pignon JP: Concomitant radio-chemotherapy based on platin compounds in patients with locally advanced non-small cell lung cancer (NSCLC): A meta-analysis of individual data from 1764 patients. Ann Oncol 2006, 1 7:473-483.

7. Schuette W, Nagel S, Blankenberg T: Phase III Study of SecondLine Chemotherapy for Advanced Non-Small-Cell Lung Cancer With Weekly Compared With 3-Weekly Docetaxel. J Clin Oncol 2005, 23:8389-8395.

8. Pectasides D, Pectasides M, Farmakis D: Comparison of docetaxel and docetaxel-irinotecan combination as second-line chemotherapy in advanced non-small-cell lung cancer: a randomized phase II trial. Ann Oncol 2005, 16:294-299.

9. Keun-Hyok Cho, Young-Bong Song, Ik-Sung Choi : A Phase II Study of Single-Agent Gemcitabine as a Second-Line Treatment in Advanced Non-Small Cell Lung Cancer. Jpn J Clin Oncol 2006, 36:50-54.

10. Weiss GJ, Rosell R, Fossella F: The impact of induction chemotherapy on the outcome of second-line therapy with pemetrexed or docetaxel in patients with advanced non-small-cell lung cancer. Ann Oncol 2007, 18:453-460.

II. Gervais R, Ducolone A, Breton JL: Phase II randomised trial comparing docetaxel given every 3 weeks with weekly schedule as second-line therapy in patients with advanced non-small-cell lung cancer (NSCLC). Ann Oncol 2005, I 6:90-96.

12. Di Maio M, Perrone F, Chiodini P: Individual Patient Data MetaAnalysis of Docetaxel Administered Once Every 3 Weeks Compared With Once Every Week Second-Line Treatment of Advanced Non-Small-Cell Lung Cancer. J Clin Oncol 2007, 25: $1377-1382$.

13. Dörthe MK, Robins HI, Martina S: Role of Tumor Necrosis Factor $\alpha$ in Hyperthermia-induced Apoptosis of Human Leukemia Cells. Cancer Res 1999, 59:3404-3410.

14. Engelhard R: Hyperthermia and drugs. Recent Results Cancer Res 1987, 104:136-203.

15. Hahn GM: Potential for therapy of drug and hyperthermia. Cancer Res 1979, 39:2264-2268.

16. Ellen LJ, James RO, Leonard RP: Randomized Trial of Hyperthermia and Radiation for Superficial Tumors. J Clin Oncol 2005, 23:3079-3085.

17. Clemens MW, Sultan AR, Matthäus K: Response to Neoadjuvant Chemotherapy Combined With Regional Hyperthermia Predicts Long-Term Survival for Adult Patients With Retroperitoneal and Visceral High-Risk Soft Tissue Sarcomas. J Clin Oncol 2002, 20:3156-3164.

18. Lindner LH, Schlemmer M, Hohenberger P: First interim report on the randomized EORTC 6296I/ESHO-RHT 95 Intergroup Study (phase III) combined with regional hyperthermia (RHT) versus chemotherapy alone in the treatment of high-risk soft tissue sarcomas (HR-STS) in adults. ASCO Meeting Abstracts 2004, 22:9015.

19. Raymond NH, Vithal KG, Michael BL: Reduction of Tumor Burden in a Murine Osteosarcoma following Hyperthermia
Combined with Cyclophosphamide. Cancer Res 1984, 44:|405-1408.

20. Kalapurakal JA, Mittal BB, Sathiaseelan V: Re-irradiation and external hyperthermia in locally advanced, radiation recurrent, hormone refractory prostate cancer: a preliminary report. Br J Radiol 200I, 74:745.

21. Vassilios EK, Costas ED, John RK: Liposomal Doxorubicin in Conjunction with Reirradiation and Local Hyperthermia Treatment in Recurrent Breast Cancer: A Phase I/II Trial. Clin Cancer Res 2002, 8:374.

22. Therasse P, Arbuck SG, Eisenhauer EA: New guidelines to evaluate the response to treatment in solid tumors. I Natl Cancer Inst 2000, 92:205-216.

23. National Cancer Institute [http://www.cancer.gov]

24. Shibata HR, MacClean LD: Blood flow to tumors. Progress Clin Cancer 1966, 2:33-47.

25. Mohamed F, Stuart OA, Glehen O: Docetaxel and hyperthermia: factors that modify thermal enhancement. J Surg Oncol 2004, 88: I4-20.

26. Yang HJ, Jiang GL, Fu XL: Radiotherapy and hyperthermia for NSCLC. ASCO Meeting Abstracts 2005, 23( I 6s):7289.

\section{Pre-publication history}

The pre-publication history for this paper can be accessed here:

\section{http://www.biomedcentral.com/1471-2407/7/189/pre} pub
Publish with Biomed Central and every scientist can read your work free of charge

"BioMed Central will be the most significant development for disseminating the results of biomedical research in our lifetime. "

Sir Paul Nurse, Cancer Research UK

Your research papers will be:

- available free of charge to the entire biomedical community

- peer reviewed and published immediately upon acceptance

- cited in PubMed and archived on PubMed Central

- yours - you keep the copyright

Submit your manuscript here:

http://www.biomedcentral.com/info/publishing_adv.asp 